\title{
Pattern of gastric emptying in the pig: relation to feeding
}

\author{
BY P. C. GREGORY*, M. MCFADYEN AND D. V. RAYNER † \\ Rowett Research Institute, Greenburn Road, Bucksburn, Aberdeen AB2 9SB
}

(Received 30 August 1989 - Accepted 4 January 1990)

\begin{abstract}
The aims of the present study were to compare the gastric emptying of dry matter (DM) and liquids during the feeding period with that following meal consumption, to clarify the relationship between feeding and gastric emptying, and to investigate how gastric emptying changes in growing animals. The studies were performed in pigs fitted with a gastric cannula and fed on a normal finely ground solid diet mixed with water containing CrEDTA as liquid marker. Gastric emptying was measured using a gastric evacuation technique. It was observed that between 0.75 and $6 \mathrm{~h}$ after feeding the total amounts emptied increased, but the proportion of the meal emptied fell, with increase in meal size; emptying of both DM and liquids with large and small meals followed an exponential pattern. In contrast, while the animals were feeding, there was linear and rapid emptying of both DM and liquids following a very short (approximately $2 \mathrm{~min}$ ) lag phase before emptying began. The rate of emptying increased linearly with body-weight (by $0.055 \mathrm{~g} \mathrm{DM} / \mathrm{min}$ and by $0.24 \mathrm{ml} / \mathrm{min}$ per $\mathrm{kg}$ body-weight over the range $58-200 \mathrm{~kg}$ ) such that the emptying of digestible energy per $\mathrm{kg}$ metabolic body-weight $\left(\mathrm{W}^{075}\right)$ was roughly maintained (between 2.9 and $3.2 \mathrm{~kJ} / \mathrm{min}$ per $\mathrm{kg} \mathrm{W}^{0.75}$ ). This suggests that the rate of emptying may be linked in some way with the metabolic requirements of the body. The biphasic pattern of gastric emptying observed is probably the intrinsic pattern of emptying of a meal which does not require breakdown of particles before emptying can occur.
\end{abstract}

Gastric emptying: Gastrointestinal tract: Pig

It has been reported that nutritious liquid meals empty from the stomach linearly, at a constant rate of energy, in man (Hunt \& Stubbs, 1975) and in monkeys (McHugh \& Moran, 1979). It has been further observed that monkeys limit their intake, when nutrients are infused into the stomach during the meal period, such as to accurately compensate for the energy infused (McHugh et al. 1975). From these findings it has been suggested that short-term regulation of energy intake in monkeys (McHugh \& Moran, 1979) and man (Hunt, 1980) may be linked to the regulation of gastric emptying of energy.

However, before this hypothesis can be accepted a number of points need clarification. Gastric emptying of a constant rate of energy has only been recorded with liquid meals, following meal consumption, and then only after an initial period of rapid emptying. The pattern of gastric emptying during the period of meal feeding remains to be determined. Furthermore, most animals eat meals that are at least partly solid in nature. In a mixed solid-liquid meal, solids empty much slower than liquids (Camilleri et al. 1985). Indeed in humans there is a long period of 15-90 min before emptying of solids begins (Camilleri et al. 1985; Horowitz et al. 1986), after which emptying of solids is linear; in contrast the liquid (mainly water) fraction of the meal empties in exponential fashion. It therefore needs

\footnotetext{
* Present address: Kali-Chemie AG, Abteilung P-FPG, Hans-Böckler-Allee 20, D-3000 Hannover I, West Germany.

$\uparrow$ For reprints.
} 
to be established how the pattern of solid emptying relates to the short-term regulation of energy intake (of a solid diet), i.e. over the feeding period. Finally, if gastric emptying is concerned with short-term regulation of energy intake it is important to know what happens to control of gastric emptying of energy in the growing animal, i.e. as the energy requirements of the body increase.

We have previously shown that the pig is able to regulate its energy intake (of a solid diet) within the course of a single meal lasting up to $45 \mathrm{~min}$, so as to compensate for the nutrients infused into the gastrointestinal tract during the meal (Gregory \& Rayner, 1987; Gregory et al. 1987), and that the stomach appears to be the site of this regulation (Gregory \& Rayner, 1986, 1987). We have also recently observed that, with variable rates of glucose infusions into the duodenum during the meal, the rate of gastric emptying of solids (dry matter; DM) is regulated such that the overall rate of energy flow through the duodenum is maintained (Gregory et al. 1988, 1989). However, other workers have reported that some glucose meals may empty exponentially rather than linearly in the pig (Reed \& Kidder, 1972); that gastric emptying of solids varies with the level of food intake (Cuber \& Laplace, 1979; Low et al. 1985) and that it decreases with time after a meal (Cuber \& Laplace, 1979; Cuber et al. 1980; Laplace et al. 1981).

In the present study we have attempted to resolve some of these apparently contrasting findings, and at the same time clarify the relationship between feeding and gastric emptying. We have measured the pattern of emptying of DM and liquids during the feeding period and that seen during the period between meals in pigs fed on a solid meal mixed with water, and have investigated over a period of 8 months how the rate of gastric emptying changes with body-weight. Brief reports of some of the results have already been published (Gregory \& Rayner, 1985; Gregory et al. 1988; Rayner \& Gregory, 1989).

\section{METHODS}

\section{Animal preparation}

Experiments were carried out on seven female Large White $\times$ Landrace pigs. Five were fitted, at a weight of $30-35 \mathrm{~kg}$, with a gastric cannula (polypropylene; barrel outer diameter $25 \mathrm{~mm}$ ), and a duodenal catheter (polyvinyl chloride; $2 \mathrm{~mm}$ outer diameter) was also implanted approximately $150 \mathrm{~mm}$ from the pylorus for a further study of the control of gastric emptying which has been reported separately (Gregory et al. 1989). The other two pigs, weighing 40 and $45 \mathrm{~kg}$, were similarly fitted with a gastric cannula and one with a reentrant cannula (Ash, 1962) in the duodenum approximately $20 \mathrm{~mm}$ from the pylorus and the other with a re-entrant cannula in the proximal jejunum about $100 \mathrm{~mm}$ aboral to the ligament of Treitz, and approximately $600 \mathrm{~mm}$ from the pylorus. All surgery was performed with full aseptic precautions under halothane anaesthesia. The animals were first sedated with Suicalm (Janssen Pharmaceuticals; $1 \mathrm{ml} / 20 \mathrm{~kg}$ intramuscularly) and then after $45 \mathrm{~min}$ they were anaesthetized with a halothane-oxygen mixture applied by face mask. Following the introduction of an endotracheal tube, anaesthesia was maintained with halothane (1-3\% as necessary) during positive pressure ventilation with an $\mathrm{O}_{2}-$ nitrous oxide mixture. Amoxycillin trihydrate BP (13 mg/kg; Clamoxyl; Beecham Animal Health) was given for at least $3 \mathrm{~d}$ after surgery.

\section{General maintenance}

The animals were allowed 2 weeks to recover from surgery and were then housed in metabolism cages under continuous lighting. They were fed to appetite and meals were offered twice daily (09.00 and 15.00 hours). The food offered (NRS9; Gregory \& Rayner 
1987), was a barley-based diet suitable for growing pigs ( $\mathrm{g} / \mathrm{kg}$ : barley 730 , soya-bean meal 175 , fish meal 65 , mineral-vitamin supplement 20 and molasses 10 , where the energy is nearly all in the solid fraction). After mixing the feed with twice its weight of water, only 46 (SE 4) g DM/1 was found in the liquid fraction which contained 1390 (SE 100) $\mathrm{mg}$ glucose/1. Each batch of food was analysed for DM content (dried at $100^{\circ}$ for $48 \mathrm{~h}$ ) and for energy value by bomb calorimetry. The mean energy content of the feed over all the experiments was $15.87 \mathrm{MJ} / \mathrm{kg}$, and the mean $\mathrm{DM}$ was $870 \mathrm{~g} / \mathrm{kg}$. In parallel studies the mean digestibility of gross energy of the diet was 0.82 (V. Fowler, personal communication), giving a mean digestible energy (DE) value for the feed of $14.95 \mathrm{MJ} / \mathrm{kg} \mathrm{DM}$. The food was also analysed for particle size. Stainless-steel sieves were placed on top of a pan, one on top of the other in ascending order of aperture size. Then, after 100-g samples of food were placed in the top sieve, all the sieves were placed on a shaker for $10 \mathrm{~min}$ after which the amount of food retained by each sieve was measured. The mean percentages of food retained in each of these sieves were 3.8 (SE 1.6), <0.15 mm; 10.4 (SE 0.9), 0.15 mm;19.2 (SE 0.7); $0.295 \mathrm{~mm} ; 32.6$ (SE 0.7), $0.599 \mathrm{~mm} ; 33.0$ (SE 1.2), $1.18 \mathrm{~mm} ; 1 \cdot 1$ (SE 0.1), $2.36 \mathrm{~mm} ; 0$, $4.75 \mathrm{~mm} ; 0,9.5 \mathrm{~mm}$.

\section{Measurement of gastric emptying of a solid meal}

Gastric emptying of the meal given at 09.00 hours was measured using a gastric evacuation technique similar to those described by Cuber et al. (1980) and Low et al. (1985). The food was thoroughly mixed before feeding with twice its weight of water which contained CrEDTA (38 mg Cr/l), prepared as described previously (Gregory et al. 1985), to allow calculation of the rate of emptying of the liquid fraction.

At $0.75,1.5,3,4.5$ and $6 \mathrm{~h}$ after the pigs had been fed, or while they were still feeding, a length of rubber tubing was connected to the barrel of the gastric cannula via a threaded tube. Warmed water $\left(1\right.$ litre at $40^{\circ}$ ) was poured into the stomach via a large funnel attached to the tubing, and the contents were briefly mixed, by raising and lowering the funnel, and then siphoned off. This process was repeated until the stomach was empty of food and CrEDTA, which was verified using a 2 litre wash; i.e. a clear wash (containing no solid and no CrEDTA) was obtained. The times for the start and finish of feeding, and of gastric evacuation were recorded.

The evacuated contents were thoroughly mixed and filtered through glass wool. All the solids were collected, dried and weighed $\left(100^{\circ}\right.$ for $\left.48 \mathrm{~h}\right)$. The volume of the filtrate was recorded and a sample was weighed and dried to allow estimation of the total DM recovered. A sample of the filtrate was analysed for $\mathrm{Cr}$ as described previously (Gregory et al. 1985). The amount of DM emptied from the stomach was then estimated:

\section{DM emptied $=\mathrm{DM}$ eaten $-\mathrm{DM}$ recovered.}

The emptying of energy from the stomach was then calculated according to the DE value of the food.

The amount of liquid emptied from the stomach was estimated thus:

$$
\text { volume emptied }=a-\frac{(b+c)[D]}{[A]},
$$

where $a$ is volume ingested, $[A]$ is initial concentration of $\mathrm{Cr}$ in the feed, $b$ is volume of filtrate (evacuation contents), $c$ is fluid volume associated with the filtered solids, $[D]$ is concentration of $\mathrm{Cr}$ in the filtrate.

Variable amounts of DM were present in the stomach following the overnight fast. Therefore the stomach was always rinsed free of any remaining digesta before measurement 
of gastric emptying. In case gastric evacuation upset gastric motility, a $1 \mathrm{~h}$ rest period was allowed before feeding the animals and the water supply was removed until after the measurement of gastric emptying.

\section{Expt I}

The two pigs (mean weight $50 \mathrm{~kg}$ ) with re-entrant cannulas were used over a period of 8 weeks to test for the completeness of recovery of digesta from the stomach using the evacuation technique described. Recoveries of liquids and solids were assessed in separate experiments using: (a) CrEDTA (Binnerts et al. 1968) as the liquid marker, and (b) mordanted Cr (Uden et al. 1980) or (c) ${ }^{103} \mathrm{Ru}$-complex (Tan et al. 1971) as the solid-phase marker.

(a) The food was mixed with twice its weight of water containing $2.1 \mathrm{ml}$ CrEDTA (18 $\mathrm{mg} \mathrm{Cr} / \mathrm{ml}) / 1$ water.

(b) Cr was mordanted onto straw (Uden et al. 1980) and this was milled through a $1 \mathrm{~mm}$ screen. The mordanted straw was mixed with the feed $(30 \mathrm{~g}$ mordanted $\mathrm{Cr}$-straw $/ \mathrm{l} \mathrm{kg}$ feed) and this was then mixed with twice its weight of water.

(c) $5 \mu \mathrm{Ci}(0 \cdot 185 \mathrm{MBq}){ }^{103} \mathrm{Ru}$ - phenanthroline complex (Tan et al. 1971) was mixed into $1 \mathrm{~kg}$ feed previously mixed with 2 litres water.

The total recovery of these markers was determined. The re-entrant cannula was opened 1-2 min before the 09.00 hours meal and all the digesta flowing from the re-entrant cannula were collected (stored on ice). After consumption of the meal the stomach contents were evacuated via the stomach cannula by the method previously described. The recovery of CrEDTA was assayed according to the method of Binnerts et al. (1968), and of mordanted $\mathrm{Cr}$ by the method of Christian \& Coup (1954). Recovery of ${ }^{103} \mathrm{Ru}$-complex was determined after drying all the collected digesta at $100^{\circ}$ for $48 \mathrm{~h}$, grinding the dried digesta in a coffee grinder (MSE Automix) and counting in a gamma counter. In some experiments the digesta flowing from the opened re-entrant cannula were collected over $1 \mathrm{~min}$ in separate samples. Samples were analysed for glucose concentration and the osmolarity was measured according to the depression of freezing point (Freezing Point Depression Osmometer; Advanced Instruments Model 3L)

Following evacuation of the stomach the pigs were re-fed until satiated after adding one sachet of Ion-aid (Syntex Pharmaceuticals), containing glycine, sodium chloride, potassium trihydrogen phosphate, magnesium sulphate, calcium gluconate, to the feed to replace any lost salts. Only one measurement was made daily.

\section{Expt 2}

Gastric emptying was measured over periods of up to $6 \mathrm{~h}$ in four pigs. Each pig was fed alternately with 900 or $1500 \mathrm{~g}$ NRS9 mixed with 1.8 and 3.0 litres water respectively at the morning meal. The gastric contents were evacuated $0.75,1.5,3,4.5$ or $6 \mathrm{~h}$ after the animals were first offered food. The sequence of the experiments was determined from a Latin square design. The contents were analysed as described for DM and CrEDTA content. After gastric evacuation at 0.75 and $1.5 \mathrm{~h}$ (but not at $3-6 \mathrm{~h}$ ) the pigs were immediately refed with $900 \mathrm{~g}$ NRS9 plus water. All of the pigs were fed until satiated at the afternoon meal. The experiment was completed over a period of 3 weeks in pigs weighing 143 $160 \mathrm{~kg}$. The results were analysed by non-linear regression $\left(y=a-b \times e^{c t}\right)$, where $a$ is the asymptote and $b$ is the difference between the intercept and the asymptote; by linear regression; and by a generalized linear modelling procedure for analysis of sigmoid data. Comparisons between curves were by $t$ test, and between individual points were by paired $t$ test. 
Expt 3(a)

The time each animal took to eat to satiety was measured in four pigs which over the course of the experiment weighed $155-200 \mathrm{~kg}$. The rate of stomach emptying was then measured over periods of one-third, two-thirds and the whole period the animals took to eat their meals. Feeding was terminated abruptly at the one-third and two-thirds periods by closing the door to the food bin. Immediately after the animals stopped eating the gastric contents were evacuated, filtered, wejghed, dried and weighed again. The amount of uneaten food was collected, dried and weighed. The amounts of DM and liquid emptied were calculated as previously described and from these values the rates of emptying were calculated by dividing by the time (min) from the start of feeding until the mid-time of the gastric evacuation procedure (Hunt \& Spurrell, 1951). Each measurement was repeated at least three and generally five times in each pig according to a Latin square design. The animals were fed until satiated after the gastric evacuation was completed. Only one measurement was made daily and the experiment was completed over a period of 6 weeks. The results were analysed by multiple linear regression and were compared using $t$ test.

\section{Expt $3(b)$}

Measurements of the rate of gastric emptying during the whole feeding period were made, as described previously, in these four pigs plus one other over a period of up to 8 months (i.e. one pig 2 months, one pig 5 months, three pigs 8 months), during which time they increased in body-weight at a linear rate of 573 (SE 36) g/d. The rates of emptying of DM and liquid observed were plotted $v$. live weight of the animals $(58-200 \mathrm{~kg})$ and analysed by multiple linear regression.

\section{RESULTS}

\section{Expt 1}

There was complete recovery of the liquid-phase marker CrEDTA (100 (SE 2) \%) in ten experiments in two pigs fed on meals of 800-2000 g NRS9, and of the solid-phase marker mordanted-Cr (100 (SE 4) \%;n 8), and nearly complete recovery of ${ }^{103} \mathrm{Ru}$-complex (94 (SE 1) $\% ; n 4)$ and DM (97 (SE 1) \%;n 12).

The best marker for DM appeared to be ${ }^{103} \mathrm{Ru}$-complex since it was recovered in similar proportions to $\mathrm{DM}$ in all fractions. In contrast mordanted-Cr showed rather different characteristics, and was emptied slower than DM.

The effect of gastric evacuation procedure on the rate of gastric emptying of DM $\left({ }^{103} \mathrm{Ru}-\right.$ complex) and liquids (CrEDTA) was then investigated. The outflow through the re-entrant cannula was collected separately during the feeding period and during the evacuation period, and the times to the start and end of feeding, and the start and end of gastric evacuation, were recorded. Dividing the amounts emptied by the time of the feeding period and by half the time to evacuate the contents respectively (Hunt \& Spurrell, 1951) gave very similar rates of emptying over the two periods: the rates of emptying of liquid $(n 5)$ were 33.8 (SE 2.3) and 39.1 (SE 3.9) $\mathrm{ml} / \mathrm{min}$ and of DM ( $n$ 4) were 5.5 (SE 0.4) and 5.4 (SE 1.9) $\mathrm{g} / \mathrm{min}$ for the feeding period and evacuation period respectively.

By collecting outflow each minute $(n 7)$ it was observed that the overall flow from the reentrant cannula was linear $(45.9 \mathrm{ml} / \mathrm{min} ; r 0.93$ from the pooled values), gastric emptying of liquids together with DM beginning on average 1.6 (SE 0.1$)$ min after the start of feeding. The pooled digesta collected during the feeding period before gastric evacuation contained 3603 (SE 343) $\mathrm{mg} / \mathrm{l}$ glucose and had a mean osmolarity of 269 (SE 9) mosmol/1 (n 7). 

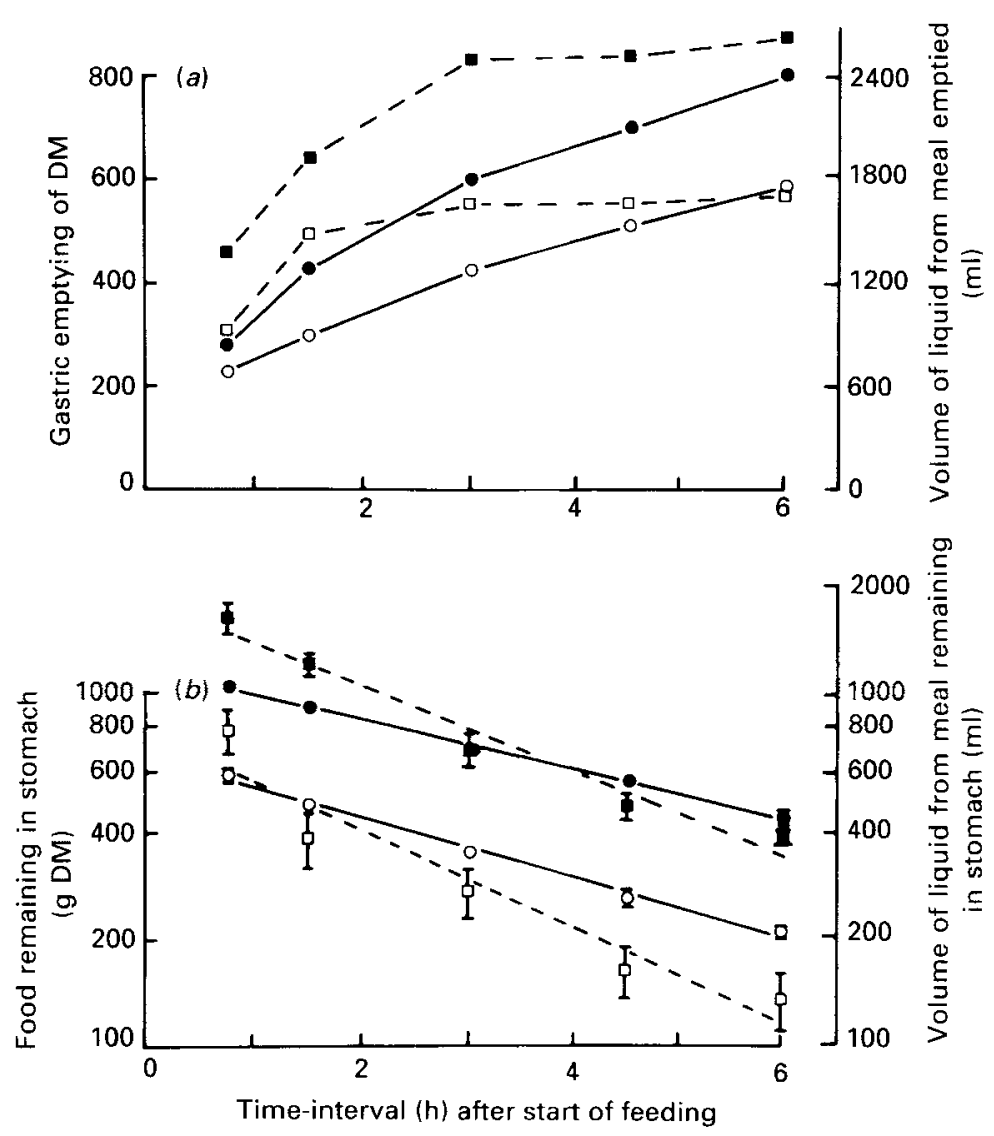

Fig. 1. Influence of meal size on the pattern of stomach emptying of dry matter (DM) and liquids after eating a solid meal (NRS9) mixed with 2 vol. water. (a) Typical results from a single pig (no. 54) show that the amounts of DM and liquids emptied from the stomach at 0.75-6 h after feeding increase with the size of the meal containing $783(\mathrm{O})$ or $1305 \mathrm{~g} \mathrm{DM}(\mathbf{O})$ and $1.8(\square)$ or 3.0 litres water $(\boldsymbol{\square})$; and follow an exponential pattern. (b) A semi$\log$ plot of the amounts of DM and liquid remaining in the stomach. Results are means, with their standard errors represented by vertical bars, for four pigs; most SE values were too small to be shown.

\section{Expt 2}

Over the period between meals $(0 \cdot 75-6 \mathrm{~h}$ after feeding), gastric emptying of DM and liquids appeared to follow an exponential pattern (Fig. 1); i.e. whether the values from each animal were analysed separately, or whether the values from all animals were plotted together, emptying of both DM and liquids was better fitted by exponential curves than by linear or sigmoid curves. However, an exponential curve did not describe the whole emptying curve, i.e. when the curve was extrapolated back to zero time to include emptying during the meal.

The amounts of DM and liquid emptied were greater with the larger than with the smaller meal at every point in time $(P<0.001$; Fig. 1$)$, but this was not due simply to proportional emptying of the meal. The proportion of both fractions of the meal emptied (Fig. 2) was significantly less with the larger than the smaller meal at most time-points, while a greater proportion of liquid than DM was emptied at every point in time $(P<0.001$, paired $t$ test) with both meals. There was no significant difference in the rate constants of DM or liquid emptying between the large and the small meals (Fig. 1(b)), nevertheless there was a tendency for the difference in amounts emptied between large and 


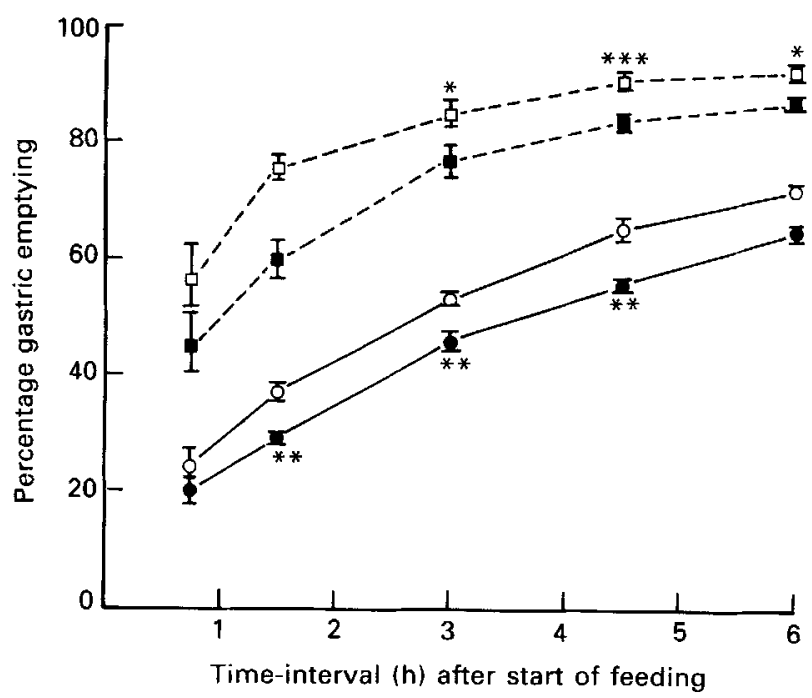

Fig. 2. Gastric emptying of dry matter $(\mathrm{DM})$ and liquids expressed as percentage of meal containing $783(\mathrm{O})$ or $1305 \mathrm{~g} \mathrm{DM}(\bigcirc)$ and $1.8(\square)$ or 3.0 litres water $(\square)$. Values are means, with their standard errors represented by vertical bars, for four pigs.

${ }^{*} P<0.05,{ }^{* *} P<0.01,{ }^{* * *} P<0.001$; by paired $t$ test for large $v$. small meal.

small meals to increase with time (Fig. 1(a)). Thus, at 45 min there was a difference of 67 (SE 12) g DM and 351 (SE 149) $\mathrm{ml}$, while at $6 \mathrm{~h}$ these differences were 279 (SE 30) g DM $(P<0.005)$ and 945 (SE 33$) \mathrm{ml}(P<0.05$; paired $t$ test). The variability between animals was small compared with the differences between the two groups (i.e. the two meal sizes). From the individual plots the mean $t_{\frac{1}{2}}$ for DM was 217 (SE 6) and 266 (SE 15) min and for liquids was 139 (SE 20) and 154 (SE 12) min for the small and large meals respectively, while for the pooled values the $t_{\frac{1}{2}}$ for DM was 216 and 271 min and for liquids was 126 and $147 \mathrm{~min}$ (Fig. $1(b))$.

\section{Expt 3(a)}

During the feeding period gastric emptying of both DM (Fig. 3) and liquids (Fig. 4) were linear. The periods the animals took to reach satiety varied considerably, but their rates of emptying of DM : $10.0(r 0.92), 10.6(r 0.93), 10.6(r 0.96)$ and $11.1 \mathrm{~g} / \mathrm{min}(r 0.96)$ and of liquids: $63.7(r 0.97), 50.6(r 0.93), 64.1(r 0.96)$ and $55.0 \mathrm{ml} / \mathrm{min}(r 0.98)$ respectively were very similar. In addition, by extrapolation from the curves there was no significant difference (paired $t$ test) in the time at which emptying of DM and liquids began; i.e. emptying of DM began at 1.5 (SE 0.8) min and of liquids at 3.3 (SE 0.7) min after the start of feeding. The mean rates of stomach emptying, obtained by plotting all the values from each animal together, were $10.9 \mathrm{~g} \mathrm{DM} / \mathrm{min}$ (Fig. $3 ; r 0.96$ ), which is equivalent to $163 \mathrm{~kJ}$ $\mathrm{DE} / \mathrm{min}$ and $58.6 \mathrm{ml} / \mathrm{min}$ (Fig. $4 ; r 0.97$ ).

\section{Expt 3(b)}

Plotting measurements of the rates of emptying over the whole feeding period (taken at different intervals over 8 months) $v$. the weight of the pigs showed a linear increase in the rate of DM emptied (Fig. $5(a) ; 0.055 \mathrm{~g} / \mathrm{min}$ per $\mathrm{kg}, r 0.89 ; P<0.001$ ) and in the rate of 
Pig no. 54

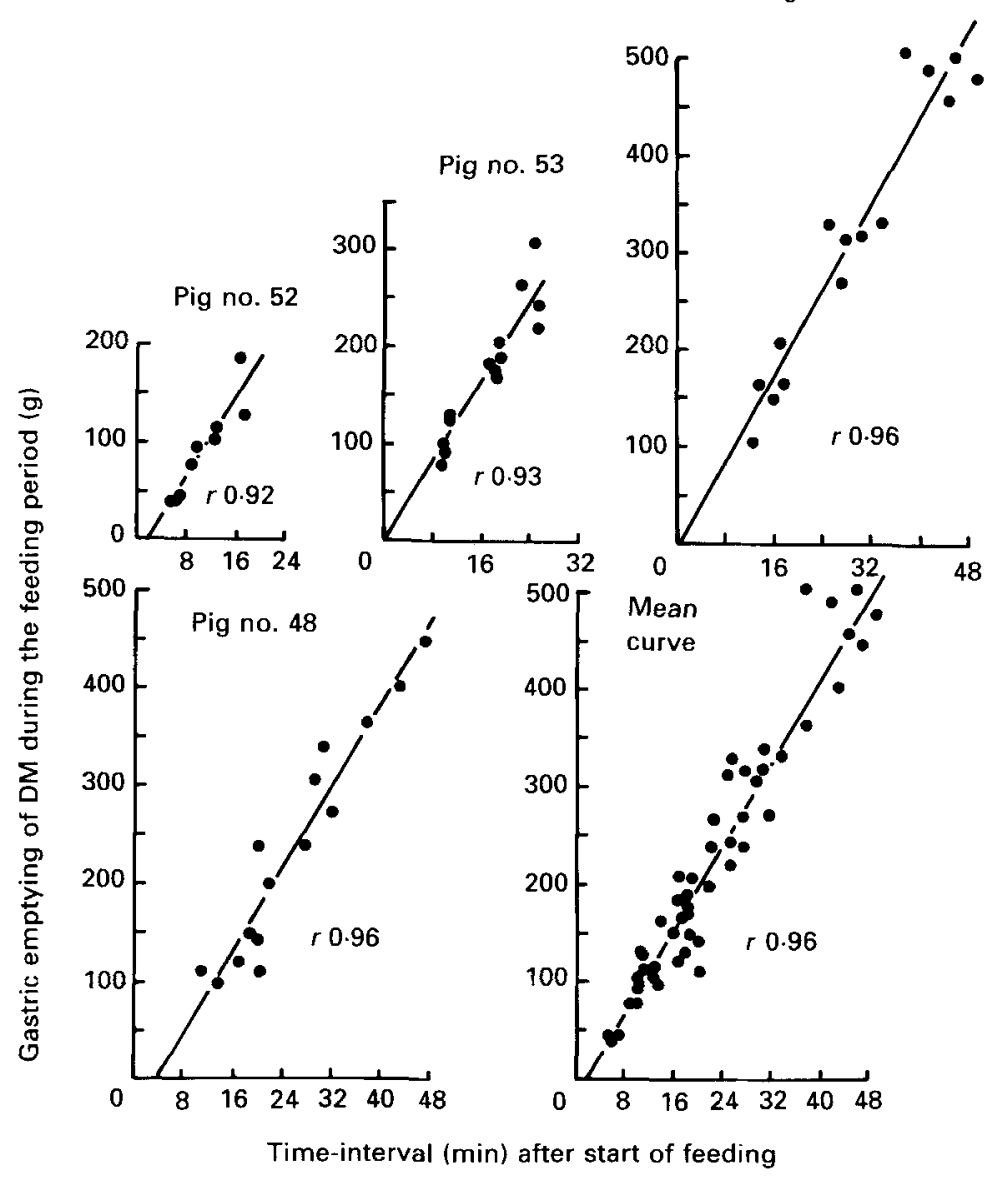

Fig. 3. The pattern of stomach emptying of dry matter (DM) during a mixed solid-liquid meal (NRS9 +2 vol. water). Individual results from four pigs show that emptying of DM is linear over the course of a meal in pigs trained to eat two $45 \mathrm{~min}$ meals daily. Mean slope $10.88 \mathrm{~g} \mathrm{DM} / \mathrm{min}, r 0 \cdot 960, P<0 \cdot 001$.

liquid emptied (Fig. 5(b);0.24 ml/min per kg, $r 0.70 ; P<0.001$ ) over the weight range $58-200 \mathrm{~kg}$. When the values for each animal were analysed individually there was evidence of different intercepts, but no difference in slopes for DM or liquid emptying $v$. bodyweight.

\section{DISCUSSION}

Gastric emptying of a solid meal mixed with water was measured using a gastric evacuation technique. Studies with pigs fitted with a re-entrant cannula showed that the gastric contents were successfully and completely removed by this technique. Gastric emptying continued during the process of evacuation. However, the amount of contents emptied during evacuation could be accounted for, and the overall rate of gastric emptying (Expt 3) could be accurately measured, by taking the experimental meal time as the time from the start of feeding until the time to mid-evacuation, as used for liquid meals (Hunt \& Spurrell, 1951). These studies also showed that although there was rapid digestion of the food within the 


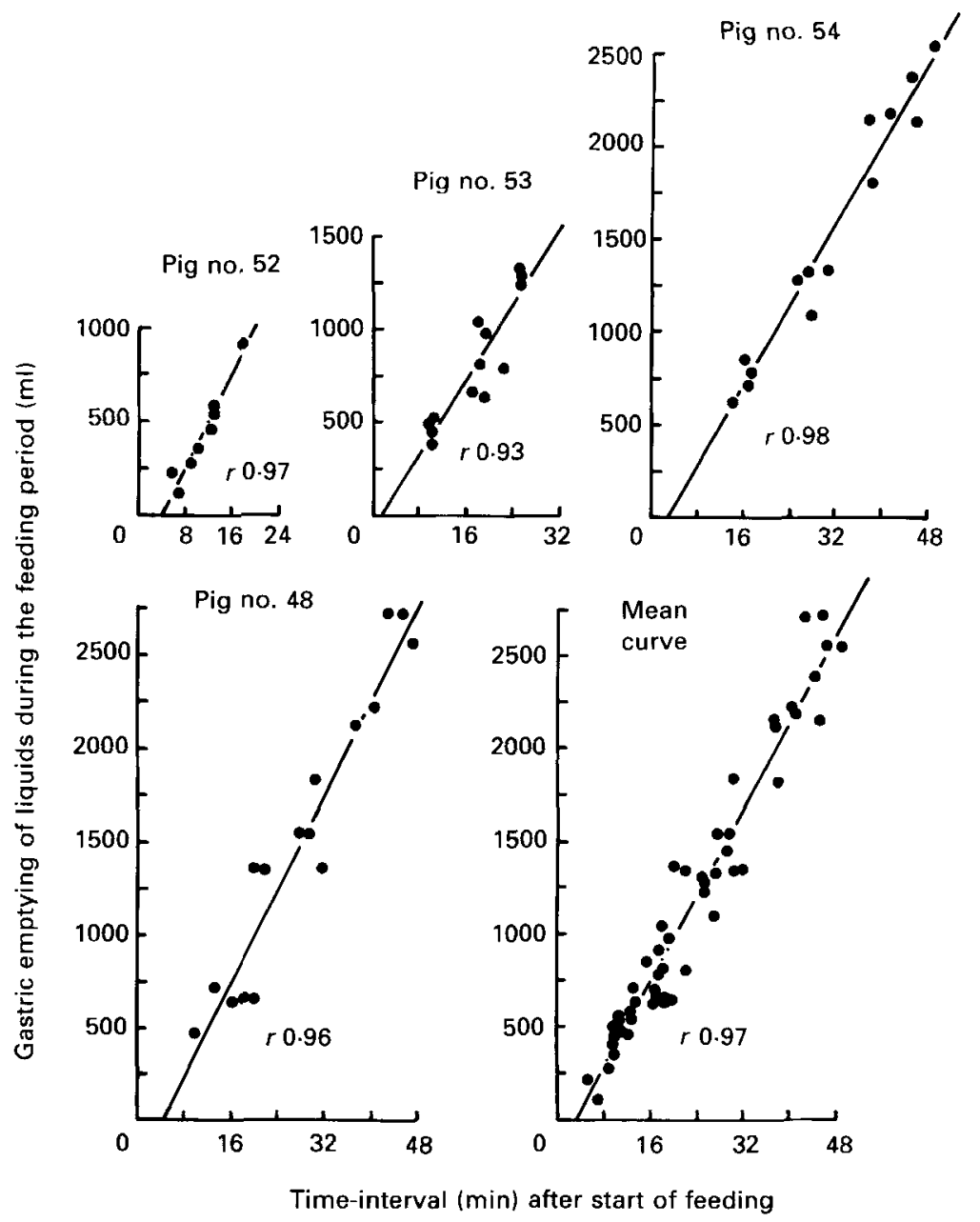

Fig. 4. The pattern of stomach emptying of liquids during a mixed solid-liquid meal (NRS $9+2$ vol. water). Individual results from four pigs shows that emptying of liquids is linear over the course of the meal. Mean slope $58.6 \mathrm{ml} / \mathrm{min} ; r 0.97 \mathrm{l}, P<0.001$.

upper small intestine (there was a $150 \%$ increase in glucose concentration), which probably explains the small loss of DM observed, the intestinal contents did not become hypertonic during the feeding period; i.e. there was no evidence that gastric emptying (or food intake) was controlled at this time according to the intestinal lumen osmolarity.

The main findings of the study confirmed and extended the previous observations, that there is an initial phase of rapid gastric emptying followed by a prolonged phase of regular and slower emptying of a mixed solid-liquid meal in the pig (Laplace \& Tomassone, 1970; Cuber \& Laplace, 1979), and showed that these were related to feeding activity. During the feeding period there was rapid linear emptying of both the solid (DM) and liquid components of the meal after a short lag phase, which for both components of the meals generally lasted for about $2 \mathrm{~min}$. Then, over a period of $6 \mathrm{~h}$, following consumption of the meal, gastric emptying of DM and liquids was slower and was better described as exponential rather than linear or sigmoidal in nature. 


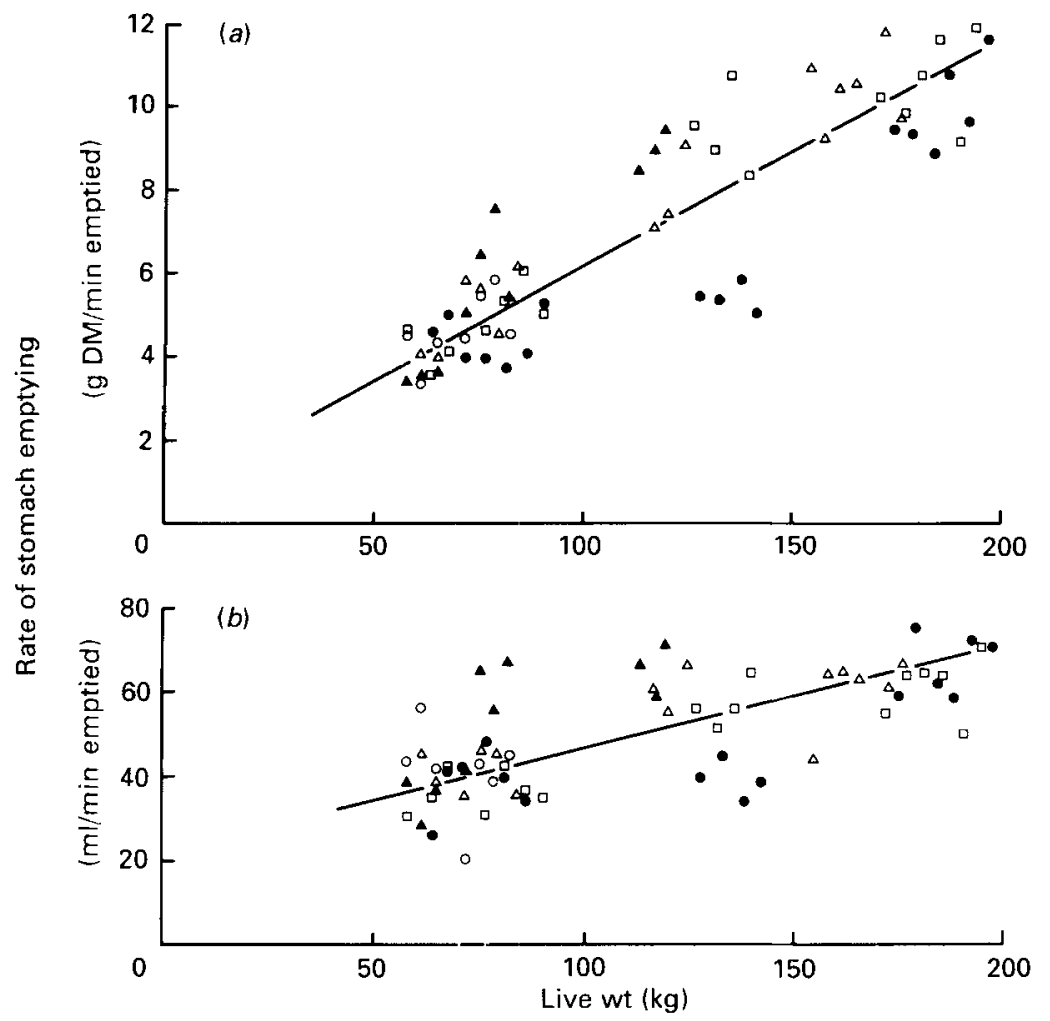

Fig. 5. The relation between body-weight and rate of stomach emptying of dry matter (DM) (a) and liquids (b) during a mixed solid-liquid meal (NRS $9+2$ vol. water). The rates of DM and liquids emptied from the stomach during the course of a meal increased linearly with the body-weight of the pigs between 58 and $200 \mathrm{~kg}$. Slope $0.055 \mathrm{~g} \mathrm{DM} / \mathrm{min}$ per $\mathrm{kg} ; r 0.889 ; P<0.001$ and $0.24 \mathrm{ml} / \mathrm{min}$ per $\mathrm{kg} ; r 0.696 ; P<0.001$. Results are from five pigs (each shown by a different symbol) fed to appetite with two meals daily.

In a parallel study, using the same diet, we recently showed that gastric emptying during the feeding period is regulated by carbohydrates so as to give a constant flow of energy to the duodenum (Gregory et al. 1989). The pig therefore appears to be similar to the rat in which it has been shown that the rate of gastric emptying of liquid meals is greater during feeding than following feeding or following gastric loading, and that emptying during feeding is regulated to give a constant outflow of energy (Kalogeris et al. 1983). In other studies of gastric emptying of liquid meals in various species, including man, monkey and rat, an initial phase of rapid emptying has been generally observed and attributed to uncontrolled emptying before activation of duodenal receptors which subsequently slow emptying (e.g. Rosenthal \& Nasset, 1958; McHugh \& Moran, 1979; McHugh et al. 1982; Brener et al. 1983). However, another explanation now seems possible, i.e. that this initial phase of rapid emptying is also regulated, albeit at a higher rate than that recorded following the meals or gastric load. It seems likely that the phase of rapid emptying relates to the filling of the stomach, in which case the duration of the phase will vary according to the duration of feeding; it remains to be determined whether the rate of emptying is affected by the rate of gastric filling.

It has been suggested that once solids are reduced to a size suitable for emptying, they are discharged at the same rate as the liquid in the stomach (Hinder \& Kelly, 1977). In the 
present study the feed given comprised $66 \%$ of particles $<1.2 \mathrm{~mm}$ and $33 \%<0.6 \mathrm{~mm}$ in diameter, i.e. below the particle size limiting emptying in dogs (Meyer et al. 1979) and humans (Meyer et al. 1981). The present meal might, therefore, be expected to empty in a somewhat similar fashion to a nutritious liquid meal (e.g. McHugh \& Moran, 1979; Brener et al. 1983) or to a homogenized meal (Malagelada et al. 1979). In fact patterns of DM and liquid emptying were similar, and the rate of emptying of DE during the meal was similar to the rate of emptying of energy in pigs given a liquid glucose diet (P. C. Gregory and D. V. Rayner, unpublished results). Nevertheless DM emptied proportionately more slowly than the liquid fraction (mainly water) of the meal (see Fig. 2). The reason for this difference needs further investigation, but it probably arises because although the food was thoroughly mixed with water before feeding no stable suspension resulted, and emptying was probably also influenced by the density of the food particles as observed in the dog (Meyer et al. 1985).

A further important observation in the present study was that the rate of gastric emptying during the meal, especially of DM, was positively and linearly correlated witk: body-weight: it remains to be determined if a similar relation exists between body-weight and rate of gastric emptying after the meal. Attempts to correlate the rate of gastric emptying (after feeding) with body-weight in adult humans have yielded equivocal results to date (Johansson \& Eklund, 1976; Lavigne et al. 1978), but it seems likely that this relationship may be most clearly demonstrated when measurements are compared at different body-weights in the same individuals rather than by comparing values from different individuals. It was previously demonstrated that the pig can accurately regulate its rate of gastric emptying so as to deliver a constant flow of energy to the duodenum during the meal (Gregory et al. 1989). It appears, therefore, that this rate of energy flow varies according to the body-weight of the animal. Since metabolic rate depends on metabolic body-weight (body-weight ${ }^{0.75} ; \mathrm{W}^{0.75}$ ) (Kleiber, 1947) one possible explanation of the relationship is that the rate of gastric emptying may be set according to the energy needs of the body, but other factors could also be involved in the present observations, e.g. increased muscularity of the stomach, increased pyloric diameter and increased duodenal capacity with increase in size of the animal.

In fact, from the data recorded (Fig. 5), it can be calculated that the emptying rate of DE increased slightly against $W^{0.75}$ as the pigs grew, i.e. from $2.9 \mathrm{~kJ} / \mathrm{min}$ per $\mathrm{kg} \mathrm{W}^{0.75}$ at $58 \mathrm{~kg}$ to $3 \cdot 2 \mathrm{~kJ} / \mathrm{min}$ per $\mathrm{kg} \mathrm{W}^{0.75}$ at $200 \mathrm{~kg}$ body-weight and, therefore, the hypothesis should be tested under conditions of altered energy requirements, e.g. cold stress.

The remainder of the study served to confirm previous observations (Cuber et al. 1980; Laplace et al. 1981) that following meal consumption there was exponential emptying of both DM and liquids in the pig. This appears to contrast with findings in other animals in which it has been generally reported that after the initial phase there is linear emptying of solids and of nutritious liquid meals, e.g. in man (Brener et al. 1983; Camilleri et al. 1985; Horowitz et al. 1986), dog (Hinder \& Kelly, 1977; Meyer et al. 1985) and the rat (Setler \& Smith, 1969; McCann \& Stricker, 1986), and exponential emptying of the liquid fraction (mainly water) of solid meals (e.g. Moore et al. 1984). However, it should be noted that in the present study, for up to $3 \mathrm{~h}$ after the meal, emptying of DM was close to linear (see Fig. 1). Since most studies have been generally made over relatively short periods (rarely more than $2 \mathrm{~h}$ ), the different pattern in emptying observed here may well relate to the longer period of observation. Indeed, in the dog, emptying of a liver meal was exponential when considered over 4-5 h but linear over the first 2-3 h (Hinder \& Kelly, 1977; Meyer et al. 1985). In man and other animals a linear pattern of emptying has been related to what has been termed 'caloric regulation of emptying', i.e. emptying is at a constant rate of energy, but such control is evidently not precise. The total amounts emptied per unit time increase 
with increase in energy density of the meal (Hunt \& Stubbs, 1975; Moore et al. 1984) and, as in thi present study, also with increase in size of the meal (Moore et al. 1984). The patterns of gastric emptying after a meal in the pig is therefore probably essentially similar to that in other animals.

The rate of emptying after meal consumption in the pig was only partly determined by gastric fill, since the proportion of the meal emptied at each point in time was less with the larger meal (see Fig. 2). It is probable, therefore, that the rate of emptying is set mainly by the balance between the positive stimulus from the level of gastric fill and negative stimuli from the duodenum dependent on the amount of energy or osmoles delivered from the stomach.

It has been suggested that in man a rapid gastric emptying might increase food intake and predispose to obesity (Hunt, 1980), and indeed it has been reported that obese subjects do have more rapid emptying than non-obese subjects (Wright et al. 1983). The rate of gastric emptying of energy in the pig appears to be rather higher than that observed in other animals, both during feeding and also after feeding. During feeding the rate of emptying of energy in the pig was $2 \cdot 9-3.2 \mathrm{~kJ} / \mathrm{min}$ per $\mathrm{kg} \mathrm{W}^{0.75}$, while in the rat, in the only comparable study, the rate of emptying was $2 \cdot 1 \mathrm{~kJ} /$ min per $\mathrm{kg} \mathrm{W}^{0 \cdot 75}$ (Kalogeris et al. 1983). Taking the almost linear period between 0.75 and $3 \mathrm{~h}$ after feeding, the rate of emptying of energy (with the two meals) was $0.58-0.87 \mathrm{~kJ} / \mathrm{min}$ per $\mathrm{kg} \mathrm{W}^{0.75}$ in the pig which is considerably greater than the rate of emptying recorded even with liquid meals of 0.36 $0.44 \mathrm{~kJ} / \mathrm{min}$ per $\mathrm{kg} \mathrm{W}^{0.75}$ in the monkey (McHugh \& Moran, 1979), of $0.37 \mathrm{~kJ} / \mathrm{min}$ per kg $\mathrm{W}^{0.75}$ in man (Brener et al. 1983) and of up to $0.37 \mathrm{~kJ} / \mathrm{min}$ per $\mathrm{kg} \mathrm{W}^{0.75}$ in the rat (McCann \& Stricker, 1986). The importance of rapid gastric emptying as a factor contributing to the pig's large appetite and propensity to lay down fat needs to be determined.

In conclusion, the present study has demonstrated that gastric emptying of both DM and liquid fractions of a finely-ground diet mixed with water follows two distinct phases in the pig; rapid linear emptying during feeding at a rate dependent in some way on body-weight, and slower exponential emptying after consumption of the meal at a rate at least partly dependent on meal size. Overall the present findings can be compared with the suggestions of Elashoff et al. (1982) that emptying of all types of meal is exponential in nature. The main difference is that Elashoff et al. (1982) attempted to explain the whole emptying curve by a single analysis (a power exponential), while, with the present diet at least, emptying follows two distinct phases. Although such an emptying pattern has not previously been reported and therefore could be peculiar to the pig, arguments have been put forward that under similar conditions this pattern may also be found in other animals. The correlation between the rate of gastric emptying during feeding and the metabolic body weight of the animals suggests that there may also be important interrelationships between the rate of gastric emptying, food intake and metabolic rate.

The authors thank Dr W. A. McKelvey, Mr C. A. Simpson and Dr F. White for assistance in the surgical preparation of the animals; Dr D. Wood for veterinary care of the animals; Mr J. Crockett and Mr S. Miller for general animal care and help in the preparation and analysis of samples, and Mrs $\mathbf{H}$. Vint for the statistical analysis of the results.

\section{REFERENCES}

Ash, R. W. (1962). Gastro-intestinal re-entrant cannulae for studies of digestion in sheep. Animal Production 4, 309-312.

Binnerts, W. T., Van't Klooster, A. T. \& Frens, A. M. (1968). Soluble chromium indicator measured by atomic absorption in digestion experiments. Veterinary Record 82, 470.

Brener, W., Hendrix, T. R. \& McHugh, P. R. (1983). Regulation of the gastric emptying of glucose. Gastroenterology 85, 76-82. 
Camilleri, M., Malagelada, J. R., Brown, M. L., Becker, G. \& Zinsmeister, A. R. (1985). Relation between antral anotility and gastric emptying of solids and liquids in humans. American Journal of Physiology 249, G580-G585.

Christian, R. R. \& Coup, M. R. (1954). Measurement of feed intake by grazing cattle and sheep. VI. The determination of chromic oxide in faeces. New Zealand Journal of Science and Technology 36A, 328-330.

Cuber, J. C. \& Laplace, J. P. (1979). Evacuation gastrique de l'amidon et de l'azote d'un régime semi-purifié à base d'amidon de mais chez le Porc. Annales de Zootechnie 28, 173-184.

Cuber, J. C., Laplace, J. P. \& Villiers, P. A. (1980). Fistulation de l'estomac et contenus gastriques résiduals après ingestion d'un régime semi-purifié à bas d'amidon de mais chez le porc. Reproduction, Nutrition, Developpement 20, 1161-1172.

Elashoff, J. D., Reedy, T. J. \& Meyer, J. H. (1982). Analysis of gastric emptying data. Gastroenterology 83, $1306-1312$.

Gregory, P. C., McFadyen, M. \& Rayner, D. V. (1987). The influence of gastrointestinal infusions of glucose on regulation of food intake in pigs. Quarterly Journal of Experimental Physiology 72, 525-535.

Gregory, P. C., McFadyen, M. \& Rayner, D. V. (1988). Regulation of stomach emptying in pigs. Journal of Physiology 396, 18P.

Gregory, P. C., McFadyen, M. \& Rayner, D. V. (1989). Control of gastric emptying in the pig: influence of duodenal infusions of glucose and emulsified fat. Quarterly Journal of Experimental Physiology 74, $109-119$.

Gregory, P. C., Miller, S. J. \& Brewer, A. C. (1985). The relation between food intake and abomasal emptying and small intestinal transit time in sheep. British Journal of Nutrition 53, 373-380.

Gregory, P. C. \& Rayner, D. V. (1985). Stomach emptying of solids in the pig: relation to feeding. Digestive Diseases and Sciences 30, 771 .

Gregory, P. C. \& Rayner, D. V. (1986). The role of stomach emptying in short-term control of food intake in pigs. Journal of Physiology 378, 25P.

Gregory, P. C. \& Rayner, D. V. (1987). The influence of gastrointestinal infusion of fats on regulation of food intake in pigs. Journal of Physiology 385, 471-481.

Hinder, R. A. \& Kelly, K. A. (1977). Canine gastric emptying of solids and liquids. American Journal of Physiology 233, E335-E340.

Horowitz, M., Collins, P. J. \& Shearman, D. J. C. (1986). Effect of increasing the caloric/osmotic content of the liquid component of a mixed solid and liquid meal on gastric emptying in obese subjects. Human Nutrition: Clinicat Nutrition $\mathbf{4 0} \mathrm{C}, 51-56$.

Hunt, J. N. (1980). A possible relation between the regulation of gastric emptying and food intake. American Journal of Physiology 239, Gl-G4.

Hunt, J. N. \& Spurrell, N. R. (1951). The pattern of emptying of the human stomach. Journal of Physiology 113, $157-168$.

Hunt, J. N. \& Stubbs, D. F. (1975). The volume and energy content of meals as determinants of gastric emptying. Journal of Physiology 245, 209-225.

Johansson, C. \& Eklund, K. (1976). Relation between body weight and gastric and intestinal handling of an oral caloric load. Gut 17, 456-462.

Kalogeris, T. J., Reidelberger, R. D. \& Mendel, V. E. (1983). Effect of nutrient density and composition of liquid meals on gastric emptying in feeding rats. American Journal of Physiology 244, R865-R871.

Kleiber, M. (1947). Bodysize and metabolic rate. Physiology Reviews 27, 511-541.

Laplace, J. P., Pons, O., Cuber, J. C., Kabore, C. \& Villiers, P. A. (1981). Effects de la nature de l'amidon (blé ou mais) et des proteines (poisson ou gluten) sur les facteurs de contrôle et le décours de l'évacuation gastrique d'un régime semi-purifié chez le porc. Applications de l'analyse multidimensionelle et de la régression polynomiale. Annales de Zootechnie 30, 209-248.

Laplace, J. P. \& Tomassone, R. (1970). Evacuation gastro-duodénale chez le porc. Annales de Zootechnie 19, 303-332.

Lavigne, M. E., Wiley, Z. D., Meyer, J. H., Martin, P. \& MacGregor, I. L. (1978). Gastric emptying rates of solid foods in relation to body size. Gastroenterology 74, 1258-1260.

Low, A. G., Pittman, R. J. \& Elliott, R. J. (1985). Gastric emptying of barley-soya-bean diets in the pig: effects of feeding level, supplementary maize oil, sucrose or cellulose and water intake. British Journal of Nutrition $\mathbf{5 4}$ 437-447.

McCann, M. J. \& Stricker, E. M. (1986). Gastric emptying of glucose loads in rats: effects of insulin-induced hypoglycemia. American Journal of Physiology 251, R609-R613.

McHugh, P. R. \& Moran, T. H. (1979). Calories and gastric emptying: A regulatory capacity with implications for feeding. American Journal of Physiology 236, R254-R260.

McHugh, P. R., Moran, T. H. \& Barton, G. N. (1975). Satiety: A graded behavioral phenomenon regulating calorie intake. Science 190, 167169 .

McHugh, P. R., Moran, T.H. \& Wirth, J. B. (1982). Postpyloric regulation of gastric emptying in rhesus monkeys. American Journal of Physiology 243, R408-R415.

Malagelada, J. R., Go, V. L. W. \& Summerskill, W. H. J. (1979). Different gastric, pancreatic and biliary responses to solid-liquid or homogenized meals. Digestive Diseases and Sciences 24, 101-109.

Meyer, J. H., Dressman, J., Fink., A. \& Amidon, G. (1985). Effect of size and density on canine gastric emptying of nondigestible solids. Gastroenterology 89, 805-813. 
Meyer, J. H., Ohashi, H., Jehn, D. \& Thomson, J. B. (1981). Size of liver particles emptied from the human stomach. Gastroenterology 80, 489-496.

Meyer, J. H., Thomson, J. B., Cohen, M. B., Shadchehr, A. \& Mandiola, S. A. (1979). Sieving of solid food by the canine stomach and sieving after gastric surgery. Gastroenterology 76, 804-813.

Moore, J. G., Christian, P. E., Brown, J. A., Brophy, C., Datz, F., Taylor, A. \& Alazraki, N. (1984). Influence of meal weight and caloric content on gastric emptying of meals in man. Digestive Diseases and Sciences 29, 513-519.

Rayner, D. V. \& Gregory, P.C. (1989). The role of the gastrointestinal tract in the control of voluntary food intake. In The Voluntary Food Intake of Pigs. Occasional Publication no. 13, British Society of Animal Production, pp. 27-39 [J. M. Forbes, M. A. Varley and T. L. J. Lawrence, editors]. Milton Keynes: British Society of Animal Production.

Reed, J. H. \& Kidder, D. E. (1972). The effect of glucose, galactose and sorbitol on gastric emptying in the young pig. Quarterly Journal of Experimental Physiology 57, 30-36.

Rosenthal, S. \& Nasset, E. S. (1958). Gastric emptying and intestinal absorption of carbohydrate and protein as influenced by the nature of the meal. Joumal of Nutrition 66, 91-103.

Setler, P. E. \& Smith, G. P. (1969). Gastric emptying in rats with chronic gastric fistulas. American Journal of Digestive Diseases 14, 137-142.

Tan, T. N., Weston, R. H. \& Hogan, J. P. (1971). Use of ${ }^{103}$ Ru-labelled tris (1,10-phenanth ruthenium(II)) chloride as a marker in digestion studies in sheep. International Journal of Applied Radiation and Isotopes 22 , 301-308.

Uden, P., Colucci, P. E. \& Van Soest, P. (1980). Investigation of chromium, cerium and cobalt, as markers in digesta - rate of passage studies. Journal of Science of Food and Agriculture 31, 625-632.

Wright, R. A., Krinsky, S., Fleeman, C., Trujillo, J. \& Teague, E. (1983). Gastric emptying and obesity. Gastroenterology 84, 747 751. 